\title{
OPERADORES ECONÓMICOS Y ESPACIOS DE COMERCIO EN EL MEDITERRÁNEO OCCIDENTAL (SIGLOS XIII-XV) ${ }^{1}$
}

\author{
David Igual Luis \\ Universidad de CAstilla-La Mancha
}

\begin{abstract}
Resumen: El artículo comienza resumiendo lo que son las características principales del comercio del Mediterráneo occidental entre los siglos XIII y XV, con especial atención a la evolución cronológica global y a sus aspectos estructurales o de fondo. Continúa analizando algunas cuestiones historiográficas y de cómo se ha desarrollado y transformado la percepción del comercio como asunto de investigación. Y termina con la observación más detallada que está actualmente en la base de muchos trabajos sobre el mundo mercantil: es la realidad del comercio local y sus posibles conexiones con otras categorías de intercambio.
\end{abstract}

Palabras clave: Comercio. Mediterráneo occidental. Baja Edad Media. Agentes económicos. Espacios mercantiles. Pequeño comercio.

\footnotetext{
1. Este trabajo forma parte de los estudios desarrollados por el autor dentro del proyecto de investigación «Migraciones, élites económicas e identidades culturales en la Corona de Aragón (1350-1500)», financiado por el Ministerio de Educación y Ciencia, y dirigido desde la Universidad de Valencia por el profesor Paulino Iradiel Murugarren, entre 2005-2008 (HUM2005-04804/HIST). Como se indica en los primeros párrafos del texto, éste se pensó como ponencia elaborada para el VI Seminario Internacional de Historia Medieval de La Nucía. Dicho seminario llevaba por título Comerciar en la Baja Edad Media: mercados, instituciones y mercaderes en el Mediterráneo y el Atlántico, y se celebró del 29 de noviembre al 1 de diciembre de 2007. Ante la imposibilidad de concretar a corto plazo la publicación de las actas del encuentro, y dado que este artículo contiene una parte de balance historiográfico (muy dependiente, por tanto, de la temporalización editorial), se decidió incluirlo en la presente revista, previo acuerdo con los organizadores del seminario. Por ello, el autor quiere agradecer a los responsables tanto del seminario como de esta revista la oportunidad de publicar aquí el trabajo.
} 
Abstract: This article starts summarizing the main characteristics of trade in the western Mediterranean between XIII and XV centuries, paying special attention to the global chronological evolution and its structural or leading aspects. It continues analysing some historiographic questions and how the perception of the trade, as a research issue, has developed and transformed. It ends with a thorough observation which is nowadays the basis of a lot of works about the commercial world: it is the reality of the local trade and its possible connection with other exchange categories.

Keywords: Trade, western Mediterranean, late middle ages, economic agents, commercial areas, retailers.

Probablemente, cuando un autor se siente obligado a comenzar la redacción de un texto con alguna justificación, como va a ser mi caso aquí, esto es síntoma de una incomodidad de entrada a la hora de acometer dicho texto $\mathrm{y}$, también quizá, del temor a que lo que se escriba al final no responda a unas mínimas exigencias científicas y acabe defraudando al lector. Y, repasando mi propia bibliografía, me doy cuenta que no es la primera ocasión en la que me asaltan estas incomodidades o temores ${ }^{2}$. Ello reproduciría, si pensamos bien, una insatisfacción recurrente ante muchos de los trabajos que elaboro o, si pensamos mal, un mecanismo de autodefensa para encubrir determinadas carencias personales de teoría, método o investigación de campo. Tal vez un buen psiquiatra o un buen psicólogo haría maravillas conmigo.

Sea como fuere, por lo que afecta en concreto al presente artículo, mis problemas se iniciaron desde el instante en que los organizadores del VI Seminario Internacional de Historia Medieval de La Nucía me invitaron a participar en él. $\mathrm{Su}$ propuesta fue que mi ponencia realizara una introducción global sobre el comercio en el Mediterráneo occidental entre los siglos XIII y XV, tomando en consideración elementos económicos, sociales y políticos. Pero esta sugerencia me provocó casi de inmediato cierta desazón, sobre todo por dos razones. La primera, por lo difícil que resulta la síntesis en este terreno de estudio. Parafraseando lo que Ivana Ait ha señalado en general acerca del comercio del Medie$\mathrm{vo}^{3}$, intentar trazar la historia del comercio bajomedieval supone prácticamente trazar la propia historia de la Baja Edad Media, vista la cantidad de variables que

2. Véanse, por ejemplo, las páginas iniciales de IguAL Luis. D., «La emigración genovesa hacia el Mediterráneo bajomedieval. Algunas reflexiones a partir del caso español», en Genova. Una «porta» del Mediterraneo, a cura di L. Gallinari, Génova, 2005, vol. I, pp. 295-328; e Idem, «Banqueros y comerciantes italianos en España en tiempos de los Reyes Católicos», en Comercio y hombres de negocios en Castilla y Europa en tiempos de Isabel la Católica, ed. por H. Casado Alonso y A. García-Baquero, Madrid, 2007, pp. 151-179.

3. Ait, I., Il commercio nel medioevo, Roma, 2005, p. 52. 
influyeron sobre los intercambios y, también, lo abundantísima que es ya desde hace tiempo la producción historiográfica al respecto. El segundo motivo de la desazón que indicaba se refiere a que proyectar la citada introducción sobre el comercio del Occidente mediterráneo podía llevarme, o al menos así lo veía yo, a repetir sin más cosas muy sabidas y que, incluso, yo mismo he comentado en varias publicaciones anteriores.

Ante esta situación, para tratar de superar tales problemas pero, a la vez, cumplir con lo que me pedía la organización del Seminario, planteé en su día una charla dividida en tres partes, que son las que ahora reitero aquí. Empezaré resumiendo las que entiendo que son las principales características del comercio entre los siglos XIII y XV, con especial atención a la evolución cronológica global y a sus aspectos estructurales o de fondo. Seguiré analizando algunas cuestiones historiográficas y de cómo se ha desarrollado y transformado la percepción del comercio como asunto de investigación. Y terminaré con la observación más detallada de una realidad que está hoy en la base de muchos trabajos sobre el mundo mercantil: es la realidad del comercio local y sus posibles conexiones con otras categorías de intercambio.

Lógicamente, a lo largo de estos puntos me detendré en temas muy diversos, entre los que destacan los dos que subraya el título del texto: el de los operadores económicos y el de los espacios de comercio. Pero, en cualquier caso, todo ello lo abordaré con un tono conscientemente generalista, que deja las precisiones para el resto de intervinientes en el Seminario y que insiste, eso sí, en argumentos y reflexiones que juzgo de interés y que he venido volcando asimismo de modo complementario en otros de mis últimos trabajos ${ }^{4}$. Aparte, aclaro también que, desde el punto de vista bibliográfico, procuraré mencionar referencias recientes cuando sea posible, siempre sin ánimo exhaustivo. Mientras, desde el punto de vista territorial, me centraré sólo en los países cristianos del Mediterráneo occidental y, dentro de ellos, cuando haya que aludir a hechos y fenómenos concretos, sobre todo en los de la Corona de Aragón 5 .

4. Como en Igual Luis, D., «¿Crisis? ¿Qué crisis? El comercio internacional en los reinos hispánicos de la Baja Edad Media», en Edad Media. Revista de Historia, 8 (2007), pp. 203-223; Idem, «Economía, mercado y comercio en la Península Ibérica (1350-1516)», eHumanista. Journal of Iberian Studies, 10 (2008), revista electrónica (www.ehumanista.ucsb.edu/volumes/volume_10/index.shtml); o Idem, «Gran comerç i petit comerç a la Corona d'Aragó. L'exemple de València a la Baixa Edat Mitjana», Imago Temporis. Medium Aevum, 3 (2009), en prensa.

5. Para observar el comercio en las zonas musulmanas del Mediterráneo remito, además de a algunas otras contribuciones de este VI Seminario Internacional de La Nucía, a la actualización de conocimientos contenida en «Relazioni economiche tra Europa e mondo Islamico. Secc. XIII-XVIII». Atti della 38a Settimana di Studi dell'Istituto Internazionale di Storia Economica «F. Datini», a cura di S. CAVACIOCCHI, Florencia, 2007, 2 vols.; y en obras más específicas como Salicrú i Lluch, R., El Sultanato Nazarí de Granada, Génova y la Corona de Aragón en el siglo XV, Granada, 2007. En relación con el comercio musulmán, particularmente 


\section{EL COMERCIO EN EL MEDITERRÁNEO OCCIDENTAL DEL SIGLO XIII AL XV}

Abro el recorrido por las tres partes que he reseñado recordando que, en el siglo XIII, se concretó la existencia de un Mediterráneo próspero y bien articulado, en cuyo seno se decidieron los papeles que marcaron en buena medida la historia comercial posterior ${ }^{6}$. No en balde, esta centuria sería el centro de lo que los estudiosos han estimado que fue, aunque con discusiones, una auténtica «revolución comercial» medieval. Que esa «revolución» focalice sus efectos sólo en el mismo Doscientos o que remita a un desarrollo en varias fases desde el siglo XI, quizá sea aquí lo menos importante 7 . Por el contrario, me interesa más resaltar el significado de dicha «revolución» como concepto que integra, en palabras de Michel Balard, las profundas modificaciones que experimentó entonces el movimiento comercial, el incremento cuantitativo de los tráficos, la extensión geográfica de las redes mercantiles, y la interferencia constante de diversos niveles de actividad que iban de lo local a lo internacional y de lo urbano a lo rural ${ }^{8}$.

En este contexto, si nos fijamos en el gran comercio marítimo, no cabe duda de que el Mediterráneo -que había venido convirtiéndose en un mar cristiano y latino desde el año mil- se vio salpicado por rutas que se multiplicaban y entrelazaban y en las que, además, desde la perspectiva técnica, se produjo particularmente desde mediados del XIII otra revolución: la llamada «revolución náutica» de la Edad Media. Ésta, a través de mejoras en los barcos y en los procedimientos de navegación, permitió aumentar la productividad del transporte marítimo, re-

el vinculado al Occidente cristiano, no habría que olvidar la conveniencia de que éste no se examine en términos únicamente imperialistas desde la cristiandad, sino también desde la lógica y la organización de las propias sociedades islámicas (Gourdin, $\mathrm{PH}$., «Pour une réévaluation des phénomènes de colonisation en Méditerranée occidentale et au Maghreb pendant le Moyen Âge et le début des Temps Modernes», en Chemins d'outre-mer. Études d'histoire sur la Méditerranée médiévale offertes à Michel Balard, textes réunis par D. Coulon et alii, París, 2004, vol. I, pp. 411-423).

6. IguAl Luis, D., «La difusión de productos en el Mediterráneo y en Europa occidental en el tránsito de la Edad Media a la Moderna», en «Fiere e mercati nella integrazione delle economie europee. Secc. XIII-XVIII». Atti della $32^{a}$ Settimana di Studi dell'Istituto Internazionale di Storia Economica «F. Datini», a cura di S. CAVACIOCCHI, Florencia, 2001, p. 458.

7. Acerca del concepto de «revolución comercial» medieval, véase el libro clásico de LóPEz, R.S., La revolución comercial en la Europa medieval, Barcelona, 1981. El debate generado por dicha noción se aprecia mejor en Ait, I., Il commercio..., cit., pp. 54-59; SPufFord, P., Power and profit. The merchant in medieval Europe, Nueva York, 2003, pp. 12-19; y TANGHERoni, M., Commercio e navigazione nel Medioevo, RomaBari, 1996, pp. 127-130 y 253-254.

8. BALARD, M., «Comercio local y comercio internacional: las mercancías», en Mediterraneum. El esplendor del Mediterráneo medieval, s. XIII-XV, coord. por E. GuEDEA, Barcelona, 2004, p. 269. 
ducir los costes y facilitar el acarreo de cargamentos en grandes cantidades 9 . Ello dio a las vías mediterráneas un impulso decisivo y, sobre todo, a la larga, aseguró la preferencia del gran comercio por los itinerarios marítimos frente a los terrestres y, también, la mayor importancia comparativa de las vías de intercambio meridionales europeas frente a las septentrionales ${ }^{10}$.

La citada proliferación de rutas acabó consintiendo la doble conexión de las costas occidentales con el Oriente mediterráneo, por un lado, y con el Atlántico, por el otro. En el primer caso, de manera simplificada, las flotas desplazaban hacia Levante paños de Flandes, Alemania, Lombardía, Cataluña y la Toscana, y traían especias, seda y objetos preciosos. Progresivamente, el valor de los productos occidentales sobrepasó al de los orientales, con lo que la balanza de pagos, que era deficitaria para el oeste europeo en torno al siglo XI, pasó a ser excedentaria a finales del Medievo ${ }^{11}$. Mientras, por lo que toca a los vínculos con el Atlántico, la conocida apertura del estrecho de Gibraltar para la navegación cristiana en la década de 1270 puso en contacto los dos grandes polos económicos de Italia y Flandes, y aumentó la importación mediterránea de lana inglesa y tejidos flamencos y franceses ${ }^{12}$. A través de ambos niveles de relación (el oriental y el oceánico), Italia quedó erigida en eje de buena parte de los grandes intercambios europeos, lo que la ha convertido desde siempre en caso digno de atención, aunque sus actividades quizá sean menos excepcionales de lo que se creía y puedan

9. Balard, M., «E1 Mediterráneo cristiano: 1000-1500», en El Mediterráneo en la Historia, ed. por D. ABULAFIA, Barcelona, 2003, pp. 187-203; Idem, «Une Méditerranée chrétienne (1000 à 1500)», en Idem, La Méditerranée médiévale. Espaces, itinéraires, comptoirs, París, 2006, pp. 17-25.

10. Massa. P., «La economía del siglo XV. Los presupuestos de la expansión europea», en EAD. et alii, Historia económica de Europa. Siglos $X V$-XX, coord. por A. Di Vittorio, Barcelona, 2003, p. 12; Palermo, L., Storia del commercio, Roma-Bari, 2000, pp. 52-53; TANGHERoni, M., Commercio e navigazione ..., cit., pp. 187-251.

11. Balard, M., «El Mediterráneo cristiano...», cit., p. 198; ID., «Une Méditerranée chrétienne ...», cit., pp. 21-22; Idem, «Comercio local...», cit., p. 278. Sobre el estado de la balanza de pagos entre Oriente y Occidente en las postrimerías de la Edad Media, véanse las hipótesis más matizadas (o directamente contrarias) con respecto a lo que digo en el texto que se exponen en ABULAFIA, D., «L'economia italiana e le economie mediterranee ed atlantiche», en L'Italia alla fine del Medioevo: I caratteri originali nel quadro europeo, a cura di F. SAlvestrini, Florencia, 2006, pp. 369-373; De Rosa, L., «Puertos, navegación, comercios mediterráneos en la época de Isabel la Católica (1474-1501)», en «Isabel la Católica y su época». Actas del Congreso Internacional, ed. por L. Riвот et alii, Valladolid, 2007, vol. I, pp. 818819; Del Treppo, M., Els mercaders catalans i l'expansió de la corona catalano-aragonesa al segle XV, Barcelona, 1976, p. 74; y TAngheroni, M., Commercio e navigazione..., cit., p. 452. Seguramente, las discrepancias acerca de este tema pueden rebajarse pensando, como dice Abulafia en la cita que acabo de indicar, que la balanza comercial no se resolvía simplemente en general con un déficit o un superávit para Oriente o para Occidente, entre otras cosas porque no todo el comercio entre ambas partes tenía el mismo carácter.

12. Balard, M.,«El Mediterráneo cristiano...», cit., pp. 203-204; Idem, «Une Méditerranée chrétienne...», cit., pp. 25-26. 
integrarse -en términos interpretativos- en un determinado universo orgánico de expansión mediterránea ${ }^{13}$.

Se ha dicho que la comunicación marítima italiano-flamenca fue uno de los factores que contribuyó a la decadencia de las famosas ferias de Champaña, las cuales habían concentrado hasta el momento las transferencias entre el norte y el sur del continente ${ }^{14}$. Pero este proceso fue paralelo también a los inicios de un incremento en la fundación de núcleos feriales por Europa, que se prolongó y aceleró hasta el siglo XV, como veremos ${ }^{15}$. A partir de entonces, las ferias acostumbraron a resultar superfluas para las mayores ciudades donde había un comercio sólido y regular, pero no siempre ocurrió igual en los centros medianos y menores. Aquí, dichas ferias dinamizaron las realidades locales y comarcales al incentivar múltiples actividades anejas, movilizar fuerza de trabajo y de distribución, y contribuir a relacionar el campo con la ciudad y, a veces, los sectores menores del tráfico con los ámbitos regional e internacional ${ }^{16}$.

Con todo ello, el Mediterráneo y las tierras a su alrededor ya eran a finales del Doscientos el corazón de diversas redes mercantiles y, al mismo tiempo, según Antoni Riera, el área más desarrollada de Occidente. Un área, también, donde no faltaron los fenómenos de concurrencia comercial y conflictividad política derivados de la rivalidad entre las potencias cristianas europeas que hacían confluir en este espacio su expansión. De hecho, en la transición del siglo XIII al XIV coincidieron en el Mediterráneo occidental dos modalidades de propagación económica y territorial: las marcadamente mercantiles (de genoveses y pisanos) y las que enfatizaban más el componente político y militar (como la de la Corona de Aragón $)^{17}$. De estas expansiones, las de Génova y la corona aragonesa pronto

13. GreCI, R., «Introduzione», en Idem et alii, Economie urbane ed etica economica nell'Italia medievale, a cura di R. GReCI, Roma-Bari, 2005, p. VI.

14. Riera i Melis, A., «El Mediterrani occidental al darrer quart del segle XIII: Concurrència comercial i conflictivitat política», en Anuario de Estudios Medievales, 26 (1996), p. 735; TANGHERONI, M., «Rapporti economici tra il Mediterraneo e l'Europa settentrionale», en Revista d'Història Medieval, 6 (1995), p. 57.

15. Igual Luis, D., «La difusión de productos...», cit., pp. 458-460; TANGHERONI, M., Commercio e navigazione..., cit., pp. 274 y $277-280$.

16. Ait, I., Il commercio..., cit., pp. 29 y 33-34; Iradiel Murugarren, P., «Ciudades, comercio y economía artesana», en «La historia medieval en España. Un balance historiográfico (1968-1998)», en XXV Semana de Estudios Medievales de Estella, Pamplona, 1999, pp. 637-638; Lanaro, P., «Introduzione», en La pratica dello scambio. Sistemi di fiere, mercanti e città in Europa (1400-1700), a cura di P. LANARo, Venecia, 2003, pp. 10-11. Sobre el significado de las ferias europeas medievales, consúltense también las distintas aportaciones publicadas en la última obra que acabo de mencionar, así como en «Fiere e mercati..., cit.; y el artículo de GrohmanN, A., «Fairs as sites of economic and cultural exchange», en Cities and Cultural Exchange in Europe, 1400-1700, ed. by D. CAlabi and S. Turk Christensen, Cambridge, 2007, pp. 207-226

17. Riera i Melis, A., «E1 Mediterrani occidental ...», cit., pp. 731 y 742-743. 
aceleraron su colisión y, al menos desde los años cercanos al 1300, se disputaron casi constantemente el liderazgo de la zona ${ }^{18}$.

No obstante, por las mismas fechas que estoy indicando (en torno a 1300), en el Occidente mediterráneo -en especial en el mundo agrario- comenzaron a verificarse algunos problemas que pueden contemplarse como los primeros síntomas de la célebre «crisis» bajomedieval. Sobre el sentido de esta crisis se ha escrito mucho, desde numerosos puntos de vista, e incluso hay ya autores que resaltan que, en general, para determinados territorios de Italia y España, la noción de «crisis» es en buena medida la importación de un modelo extranjero, más válido para los medievalistas franceses, alemanes y anglosajones ${ }^{19}$. En el terreno comercial, las polémicas al respecto han venido enfatizando, básicamente para el tráfico internacional, las condiciones coyunturales o estructurales de la propia crisis. Y también, han venido limitando la aplicación del concepto a un siglo XIV caracterizado, en todo o en parte, por la depresión económica o, por el contrario, han prolongado su significado al conjunto de los siglos XIV y XV remarcando, en paralelo, la capacidad de recuperación del Cuatrocientos y las transformaciones de la vida mercantil. Más allá de estas diferentes interpretaciones, creo que se puede afirmar que hoy predominan los historiadores que adoptan ante la cuestión posturas calificables de «optimistas», ya que consideran superado el argumento de una recesión generalizada en la época del comercio internacional, y hasta analizan el movimiento mercantil en un marco que destaca los aspectos económicamente más dinámicos y cambiantes del período ${ }^{20}$.

18. Petti Balbi, G., Negoziare fuori patria. Nazioni e genovesi in età medievale, Bolonia, 2005, p. 125. Las muestras de concurrencia comercial y política entre Génova y la Corona de Aragón son numerosas a lo largo de la Baja Edad Media, como se aprecia en Ferrer i Mallol, Ma.T., «I Genovesi visti dai Catalani nel Medioevo. Da amici a nemici», en Genova, una «porta» del Mediterraneo, cit., pp. 137-174; SALICRÚ i LLuCH, R., «Una lluita per un mercat: catalans, algueresos i genovesos i el corall de Sardenya a la primeria del segle XVI», en La Corona catalanoaragonesa i el seu entorn mediterrani a la Baixa Edat Mitjana, ed. per Ma.T. Ferrer i Mallol et alii, Barcelona, 2005, pp. 309-362; El Sultanato Nazarí de Granada..., cit.

19. Menant, F., «Crisis de subsistencias y crisis agrarias en la Edad Media: algunas reflexiones previas», en Crisis de subsistencia y crisis agrarias en la Edad Media, ed. por H.R. Oliva Ferrer y P. Benito i Monclús, Sevilla, 2007, p. 22. Esta misma obra colectiva, junto al dossier monográfico «La crisis del siglo XIV en los Reinos Hispánicos», en Edad Media. Revista de Historia, 8 (2007), pp. 37-328, constituyen dos buenas actualizaciones de la problemática general de la «crisis», sobre todo en relación con la España bajomedieval. También son básicas al respecto las reflexiones contenidas en CASADO Alonso, H., «¿Existió la crisis del siglo XIV? Consideraciones a partir de los datos de la contabilidad de la catedral de Burgos», artículo que aparecerá en el volumen de homenaje a Julio Valdeón Baruque con motivo de su jubilación (Valladolid, en prensa). Agradezco al profesor Hilario Casado que me facilitara este texto antes de ser editado. Para un análisis sintético a escala europea, recúrrase mejor a Iradiel Murugarren, P, «La crisis bajomedieval, un tiempo de conflictos», en "Conflictos sociales, políticos e intelectuales en la España de los siglos XIV y XV». XIV Semana de Estudios Medievales de Nájera, coord. por J.I. De La Iglesia Duarte, Logroño, 2004, pp. 18-31.

20. Las líneas anteriores acerca de la crisis en el comercio sintetizan el extenso balance sobre el particular que he ofrecido en Igual Luis, D., «¿Crisis? ¿Qué crisis?...», cit., y en Idem, «Economía, mercado...», cit. 
Sobre lo primero (la superación del contexto recesivo), es cierto que los efectos globales de la peste negra de 1348 y algunos datos concretos investigados para los mismos años de mitad del XIV (por ejemplo, en Génova y Barcelona) han abonado tradicionalmente la hipótesis de una contracción palmaria del comercio marítimo de la Baja Edad Media, en comparación con el de fines del siglo XIII. Pero esta idea ha sido muy matizada tras comprobar las trayectorias en ocasiones divergentes de los países mediterráneos, la tendencia de larga duración (mantenida como mínimo hasta 1500) hacia el crecimiento general del transporte tanto en número de naves como en volumen de mercancías $\mathrm{y}$, sobre todo, las oscilaciones de la coyuntura ${ }^{21}$.

A escala europea, Peter Spufford ha reiterado recientemente la importancia de tales oscilaciones. Y a la vez ha insistido en los ritmos internos distintos con que se desarrollaba la economía de cada sociedad, los cuales podían aportar imágenes simultáneas de prosperidad o de apuro según los sectores sometidos a examen ${ }^{22}$. Mientras, a nivel regional, uno de los casos donde el peso de las coyunturas se ha reivindicado más es el de Barcelona. Sin entrar en el amplio debate sobre lo que ocurrió en el comercio catalán de los siglos XIV y XV, sí se puede señalar que la historiografía está cada vez más alejada de las posiciones que abogaban por una decadencia global y duradera del citado comercio. Y lo está, entre otros motivos, por la mayor precisión con que se ha definido la cronología. Así, Gaspar Feliu ha defendido que entonces se sucedieron en Cataluña varios momentos de dificultad y de expansión, dentro de los cuales sólo a partir de 1415 aparecieron determinados problemas del tráfico exterior que vendrían marcados por causas como la reducción del principal eje comercial catalán en sus dos extremos (Oriente y Flandes). Además, por lo que toca al comercio con Oriente, también Damien Coulon ha desmentido la noción de largo declive del contacto de Barcelona con Egipto y Siria, al asumir las diferentes fases por las que éste pasó: aguda crisis negativa entre 1350-1370; máxima actividad entre 1370-1430; nuevos obstáculos entre 1433-1454; recuperación entre 1454-1460; y definitivo repliegue desde 1462, en consonancia con los efectos de la guerra civil catalana ${ }^{23}$.

21. Sobre los datos y los matices indicados, véase BALARD, M., «El Mediterráneo cristiano ...», cit., pp. 204206; Idem, «Une Méditerranée chrétienne ...», cit., p. 26; Coulon, D., «Comercio y navegación occidentales hacia el Levante mediterráneo (siglos XIII-XV)», en Mediterraneum ..., cit., pp. 296 y 298; y TANGHERONI, M., Commercio e navigazione ..., cit., pp. 457-463.

22. SPufFord, Power and profit ..., cit., p. 389.

23. Feliu, G., «La crisis catalana de la Baja Edad Media: estado de la cuestión», en Hispania, LXIV/2, nº 217 (2004), pp. 457-460 y 465; Coulon, D., Barcelone et le grand commerce d'Orient au Moyen Âge. Un siècle de relations avec l'Égypte et la Syrie-Palestine (ca. 1330 - ca. 1430), Madrid-Barcelona, 2004, pp. 607612. Aparte del tráfico con Oriente, otro de los comercios importantes de Barcelona durante la Baja Edad 
El profesor Riera aseguró hace tiempo que, en la Cataluña bajomedieval, lo que estaba en discusión era el alcance de la crisis y su secuenciación, no tanto la existencia de una serie de transformaciones cuantitativas y cualitativas que eran aceptadas por todos ${ }^{24}$. Pues bien: como he apuntado antes, justo la realidad de dichas transformaciones en el comercio (catalán y no catalán) de esta etapa es otro de los asuntos que más preocupa actualmente a la investigación que centra su interés en el Mediterráneo occidental. De todos los cambios estudiados, me limito a comentar los rasgos esenciales de cuatro de ellos, que son muy conocidos por otra parte ${ }^{25}$.

El primero, las adaptaciones técnicas de los transportes y los negocios, surgidas en el seno de las condiciones de la economía desde 1300 y, a veces, como respuesta a ellas. Al respecto, cabe reseñar que las embarcaciones siguieron su evolución, con la posibilidad de trabajar con tonelajes mayores, pero también de disponer de barcos menores para atender las necesidades de los diversos niveles de comercio. En la construcción y explotación de las naves se introdujeron elementos de división de riesgos, de aseguración del tráfico y de discriminación en el precio de los fletes, los cuales consolidaron lógicas que ya sabemos: rebajar costes y facilitar grandes circulaciones de productos ${ }^{26}$. Sin duda, estos elementos entrarían de lleno en lo que se ha denominado el «poder del saber mercantil»» ${ }^{27}$. Un poder que, para los operadores medianos y mayores del continente, quedó reforzado con la creación de compañías. Algunas de éstas formaron verdaderos sistemas de empresas con agentes dispersos por todo el Mediterráneo, con una buena red de información, y con el uso de innovadores métodos financieros y contables $^{28}$.

Media (el mantenido con Flandes), ha merecido también una monografía propia: PIFARRé Torres, D., El comerç internacional de Barcelona i el Mar del Nord (Bruges) al final del segle XIV, Barcelona, 2002.

24. Riera Melis, A., «El comerç català a la Baixa Edat Mitjana. I: El segle XIV», en Annals de la Segona Universitat d'Estiu: «La Baixa Edat Mitjana», Andorra, 1984, p. 194.

25. Y que se reiteran en casi cualquier síntesis de la economía de la época, como en EPSTEIN, S.R., «I caratteri originali. L'economia», en L'Italia alla fine del Medioevo ..., cit., pp. 381-431.

26. Balard, M., «El Mediterráneo cristiano ...», cit., p. 209; ID., «Une Méditerranée chrétienne ...», cit., pp. 27-28; TAngheroni, Commercio e navigazione ..., cit., pp. 459-462.

27. CAsado Alonso, H., «El comercio internacional castellano en tiempos de Isabel la Católica», en «Isabel la Católica y su época» ..., cit., pp. 654-655. Del mismo autor, véase también otra publicación reciente: «Los flujos de información en las redes comerciales castellanas de los siglos XV y XVI», en Investigaciones de Historia Económica, 10 (2008), pp. 35-68.

28. Sobre compañías, redes informativas y técnicas financieras y contables, es útil la lectura de los trabajos que cito en las dos notas anteriores. Y asimismo, últimamente, de las obras colectivas Écrire, compter, mesurer. Vers une histoire des rationalités pratiques, sous la dir. de N. CoQuery et alii, París, 2006, y Correspondence and Cultural Exchange in Europe, 1400-1700, ed. by F. Bethencourt and F. Egmond, Cambridge, 2007. Consúltese también Cruselles Gómez, E., Los comerciantes valencianos del siglo XV y sus libros 
El segundo de los cambios que he mencionado tiene que ver con la demanda y el consumo. Habituados a observar el comercio desde el lado de la producción y la venta, los historiadores hemos olvidado normalmente que, en las sociedades preindustriales, el consumidor era el rey y que, aunque los desarrollos de la demanda y la oferta fueron simultáneamente significativos, la primera acostumbraba a importar más que la segunda ${ }^{29}$. En este terreno, las modificaciones de la Baja Edad Media fueron sustanciales. El incremento del poder adquisitivo de ciertos grupos urbanos y rurales propició pautas de compra amplias y diversificadas, que beneficiaron -y mucho- a la transferencia de tejidos, pieles y otras manufacturas, objetos domésticos, artículos ganaderos y lácteos, y vituallas exóticas o de calidad como el vino, el aceite, los frutos secos y el azúcar. En definitiva, es el «imperio de las cosas» del que hablaba Richard Goldthwaite ${ }^{30}$ que favoreció, junto a algunos de los adelantos técnicos citados, la mejor integración del comercio de productos ricos y lujosos con el tráfico de materias de menor valor y prestigio, pero que gozaron de sólida demanda en los pueblos y ciudades euromediterráneos.

Muy conectado con todo esto, el tercer cambio a comentar afectó a la proliferación de mercados locales y regionales, en paralelo al crecimiento del comercio interior terrestre. Partiendo de casos de la Corona de Aragón, David Abulafia ha ratificado que todo el período posterior a la peste negra de 1348 se caracterizaría por la intensificación de las relaciones de media y breve distancia, y hasta por ser la «edad de oro» de los intercambios locales ${ }^{31}$. Pero el proceso fue más general $\mathrm{y}$, en el ámbito europeo, quedó vinculado a la constante creación y renovación de ferias y mercados, a la regionalización de las economías continentales, y al acceso de sectores campesinos y humildes a las dinámicas del propio mercado.

de cuentas, Castellón, 2007, pp. 11-148; y OrLANDI, A., «Estudi introductori», en Mercaderies i diners: la correspondència datiniana entre València i Mallorca (1395-1398), a cura d'A. ORLand, Valencia, 2008, pp. 11-59.

29. Spufford, P., Power and profit ..., cit., pp. 408-409; Dyer, Сн., Niveles de vida en la Baja Edad Media, Barcelona, 1991, p. 23; Idem, "The Consumer and the Market in the Later Middle Ages», en ID., Everyday Life in Medieval England, Londres, 2000, p. 257.

30. Según se recoge en CASAdo Alonso, H., «El comercio internacional castellano ...», cit., pp. 655-656, a partir de Goldthwaite, R.A., «The Empire of Things: Consumer Demand in Renaissance Italy», en Patronage, Art and Society in Renaissance Italy, ed. by F.W. Kent et alii, Oxford, 1987, pp. 153-175.

31. Abulafia, D., «L'economia mercantile nel Mediterraneo Occidentale: commercio locale e commercio internazionale nell'età di Alfonso il Magnanimo», en XVI Congresso Internazionale di Storia della Corona d'Aragona: «La Corona d'Aragona ai tempi di Alfonso il Magnanimo», a cura di G. D'Agostino e G. Buffardi, Nápoles, 2000, vol. II, p. 1025; Idem, «Mercati e mercanti nella Corona d'Aragona: Il ruolo degli imprenditori estranieri», en XVIII Congrés Internacional d'Història de la Corona d'Aragó: «La Mediterrània de la Corona d'Aragó, segles XIII-XVI» \& «VII Centenari de la Sentència Arbitral de Torrellas, 1304-2004», a cura de R. Narbona VizCaíno, Valencia, 2005, vol. I, pp. 803 y 810-811. 
Además, esta expansión de lo local y lo regional debió ayudar a formar un contexto positivo para el comercio internacional marítimo. Y es que todos los circuitos mercantiles pudieron llegar a establecer entre sí múltiples interacciones, con lo que el crecimiento de unos no tuvo necesariamente que perjudicar a los otros, como ya dejó asentado en su día Marco Tangheroni ${ }^{32}$.

La cuarta y última transformación que quería resaltar apunta a la geografía de los intercambios. En esta geografía sobresale la emergencia de la Península Ibérica como espacio donde no sólo la comercialización de bienes y servicios penetró la mayoría de aspectos de la economía, sino donde también convergieron la atracción de iniciativas europeas, la promoción de los famosos descubrimientos marítimos, y la interrelación entre el Mediterráneo y el Atlántico, bien demostrada mediante la presencia creciente de operadores castellanos y portugueses en las costas mediterráneas, por ejemplo ${ }^{33}$. Para algunas regiones peninsulares, tal situación debe verse motivada por las nuevas posibilidades ofrecidas a las economías secundarias que eran escala de las grandes rutas marítimas ${ }^{34}$. Pero, en el éxito mercantil, el peso de esta demanda externa se combinó muchas veces con el de la demanda interna, con lo que en el desarrollo ibérico acabaron influyendo numerosas variables concretadas en factores de complementariedad y concurrencia, ya sea dentro de un mismo territorio, ya sea entre territorios diferentes ${ }^{35}$.

Con la suma de ingredientes que hemos visto (y de otros que me ahorro exponer), el gran comercio desplazó con lentitud su eje hacia Occidente, mientras el Mediterráneo continuaba siendo encrucijada de itinerarios y redes de nego$\operatorname{cios}^{36}$. Y lo era a pesar de todos los problemas bajomedievales, de los altibajos de algunas plazas mercantiles, de las ocasionales diferencias evolutivas entre espacios, y de lo desigual que resultó la aplicación de los mecanismos de trans-

32. TAngheroni, Commercio e navigazione ..., cit., pp. 393-394 y 457.

33. La Península Ibérica entre el Mediterráneo y el Atlántico. Siglos XIII-XV, ed. por M. GonZÁLez JiMÉneZ e I. Montes Romero-Camacho, Sevilla-Cádiz, 2006; Portogallo mediterraneo, a cura di L. AdÃo da FonseCA e M.E. CAdeddu, Cagliari, 2001; AdÃo DA FonseCA, L., Dal Mediterraneo all'Atlantico. Le scoperte e la formazione del mare oceano nei secoli XIV-XVI, Pisa, 2004.

34. Cruselles Gómez, E., «Los mercados aseguradores del Mediterráneo catalano-aragonés», en «Ricchezza del mare, ricchezza dal mare. Secc. XIII-XVIII». Atti della $37^{a}$ Settimana di Studi dell'Istituto Internazionale di Storia Economica «F. Datini», a cura di S. CAVACIOCCHI, Florencia, 2006, vol. I, p. 611.

35. Asenjo GonzÁlez, M., «El comercio. Actividad económica y dinámica social en las plazas y mercados de Castilla. Siglos XIII-XV», Cuadernos del CEMyR, 9 (2001), pp. 97-134; Iradiel Murugarren, P., «El comercio en el Mediterráneo catalano-aragonés: espacios y redes», en Comercio y hombres de negocios en Castilla y Europa ..., cit., pp. 123-150; THEMUdo BARATA, F., Navegação, comércio e relações políticas: os portugueses no Mediterrâneo ocidental (1385-1466), Lisboa, 1998.

36. AbulafiA, D., «Italia e lo spostamento economico del XV secolo», en El Mediterráneo medieval y renacentista, espacio de mercados y de culturas, ed. por J. Aurell, Pamplona, 2002, pp. 179-212; Idem, «L'economia italiana ...», cit., pp. 355-380. 
formación. Durante la segunda mitad del siglo Xv, también a pesar de los avances oceánicos, este Mediterráneo seguía mostrando importantes signos de vitalidad económica en su vertiente occidental, en una imagen de recuperada prosperidad donde, a las dinámicas del ya tradicional binomio constituido por la Corona de Aragón y Génova, se unieron entre otros -y ya venían haciéndolo desde bastante tiempo atrás- los esfuerzos de Venecia (con la circulación intermarítima de sus galere da mercato), Florencia (con su modelo de grandes aziende), y los países atlánticos que, como he dicho, penetraban en el mar interior ${ }^{37}$.

\section{ENTRE EL GRAN Y EL PEQUEÑO COMERCIO: LA EVOLUCIÓN DE LA HISTORIOGRAFÍA}

Hasta aquí el resumen recordatorio, apresurado, de las principales líneas del comercio mediterráneo entre los siglos XIII y XV. Como se habrá comprobado, en ese resumen he privilegiado la visión del gran tráfico internacional, sin desdeñar referencias a lo que podemos llamar el pequeño comercio de carácter local o interior. En realidad, sin embargo, un balance completo exigiría mostrar más equilibrio entre ambos horizontes comerciales (el internacional y el local). Un equilibrio al que se va acercando poco a poco la historiografía, gracias a algunas variaciones de perspectiva que conviene anotar. Entro ya, así, en la segunda parte del trabajo.

José Ángel Sesma, en el examen del comercio como objeto de investigación con que abrió la Semana de Estudios Medievales de Nájera del año 2005, señaló una evolución europea de dicha historiografía por la que, dentro del siglo xx, distinguía una primera fase consagrada al estudio de las grandes operaciones económicas, los circuitos internacionales y los fenómenos de alta finanza. Esta fase llegaría hasta comienzos de la década de 1980, cuando la influencia de ciencias sociales como la antropología y la economía permitió que la historia comercial, sin marginar las mayores manifestaciones de los intercambios, comenzara a diseccionar también de manera exhaustiva el comercio más próximo que enlazaba

37. Aymard, M., «La fragilità di un'economia avanzata: l'Italia e le trasformazioni dell'economia europea», en Storia dell'economia italiana, a cura di R. Romano, Turín, 1991, vol. II, pp. 5-12; Iradiel Murugarren, P., «El comercio en el Mediterráneo entre 1490 y 1530», en Congreso internacional «De la unión de coronas al Imperio de Carlos V», coord. por E. Belenguer CebriÁ, Madrid, 2001, vol. I, pp. 92-105; De Rosa, P., «Puertos, navegación, comercios mediterráneos ...», cit., pp. 807-822. Sobre los desarrollos veneciano y florentino, véase Hocquet, J.-C., Venise et la mer, XII ${ }^{e}$-XVIII ${ }^{e}$ siècle, París, 2006; Dini, B., Saggi su una economia-mondo. Firenze e l'Italia fra Mediterraneo ed Europa (secc. XIII-XVI), Pisa, 1995; e Idem, Manifattura, commercio e banca nella Firenze medievale, Fiesole, 2001. Aparte, para observar la repercusión particular de los convoyes de galeras venecianas en un área como la española, véase el balance realizado por LóPez de Coca CASTAÑer, J.E., «Las galeras venecianas de Poniente y Berbería desde la perspectiva española», en Medievalismo, 16 (2006), pp. 113-172. 
con la relación campo-ciudad y con los ámbitos locales y regionales. Con ello se recalcaba el hecho de que los elementos derivados de este tipo de comercio incidían directamente en los comportamientos más profundos de la economía. Pero, siempre según Sesma, el punto clave de esta nueva orientación quizá sería la sustitución del concepto «comercio» por el de «mercado» ${ }^{38}$. Si la idea de «comercio» implica la mera negociación de compraventa o permuta de mercancías, por «mercado» debemos entender una noción más amplia que, como es sabido, aparte de indicar espacio físico, integra asimismo el lugar teórico de encuentro entre oferta y demanda por parte de los agentes económicos, con el contexto que les ofrecen determinadas estructuras e instituciones sociales ${ }^{39}$.

También últimamente, un encuentro celebrado en Amberes el año 2003 -que se dedicó a las prácticas de venta al detalle en la Europa del tránsito de la Edad Media a la Moderna- ha reiterado que la observación del pequeño comercio constituye hoy una cuestión básica para la historiografía. Mucho más cuando tal observación se sitúa en el debate sobre el grado de modernidad de la sociedad continental antes de la época contemporánea. En este sentido, y al menos para el siglo Xv, las conclusiones del citado encuentro han confirmado, por ejemplo, la coexistencia e interacción de diversos sistemas de distribución minorista (desde los mercados semanales y el comercio itinerante hasta las tiendas permanentes); la concentración física de las tiendas que solía producirse en áreas específicas de algunas ciudades; la repercusión también aquí de la circulación de mayor variedad y cantidad de artículos que con respecto a etapas anteriores, y para un número más abundante de consumidores; y finalmente, la importancia que tenían en el despliegue de esta escala de mercado los vínculos personales y la posición laboral de las mujeres, quienes llegaban a ocupar estatus elevados ${ }^{40}$. Son argumentos, en definitiva, interesantes (aunque no creo que sean tan novedosos como

38. Sesma MuÑoz, J.Á., «El comercio en la Edad Media (Reflexiones para abrir una Semana de Estudios Medievales)», en «El comercio en la Edad Media». XVI Semana de Estudios Medievales de Nájera, coord. por J.I. DE la Iglesia Duarte, Logroño, 2006, pp. 17-19. Compárese la evolución historiográfica diseñada por Sesma con la que, de modo muy parecido, se recoge en Igual Luis, D., «Economía, mercado ...», cit.

39. BRITNELL, R.H., «Local trade, remote trade: Institutions, information and market integration, 1050-1330», en «Fiere e mercati ... cit., p. 185; Igual Luis, D., «La difusión de productos ...», cit., p. 467; TANGHERONI,M., Commercio e navigazione ..., cit., pp. 270-271.

40. BlondÉ, B. et alii, «Retail circuits and practices in medieval and early modern Europe: an introduction», en Buyers and Sellers. Retail circuits and practices in medieval and early modern Europe, ed. by B. BLONDÉ et alii, Turnhout, 2006, pp. 7-29, especialmente pp. 7, 9, 12 y 19-20; STABEL, P., «From the market to the shop. Retail and urban space in late medieval Bruges», en Ibídem, pp. 79 y 103-104; KeENE, D., «Sites of desire: shops, selds and wardrobes in London and other English cities, 1100-1550», en Ibídem, pp. 138139 y 144-149. Con argumentos parecidos a los de estas tres contribuciones al encuentro mencionado de Amberes, véase también Welch, E., Shopping in the Renaissance. Consumer Cultures in Italy, 1400-1600, New Haven-Londres, 2005. 
los presentan los editores del encuentro), y que surgen tanto de una concepción muy culturalista de la historia económica como de la propia colaboración entre historiadores, economistas y antropólogos.

En mi opinión, como también escribía hace poco Hilario Casado, ópticas de análisis como éstas han conducido a una visión más compleja del panorama mercantil, la cual ha permitido enfatizar ya modelos polinucleares o multilaterales de relación a nivel tanto social como territorial ${ }^{41}$. Son modelos que, estableciendo la existencia real de formas y redes de integración, han apreciado cómo el movimiento comercial medieval fomentaba distintas categorías de desarrollo que no sólo no eran excluyentes entre sí, sino que se interconectaban. Éstas últimas vuelven a ser palabras de José Ángel Sesma ${ }^{42}$, que van en la misma línea de algunas afirmaciones a las que antes he aludido del profesor Marco Tangheroni.

Desde luego, el diseño más intrincado de los intercambios también ha pasado por lo que sería una reivindicación del papel histórico del pequeño comercio. Según avanzaba el período de finales de la Edad Media, éste resultó cada vez más decisivo para el mantenimiento de la economía. Además, no olvidemos que el principio y el final de muchas cadenas mercantiles -incluyendo algunas que transitaban por rutas marítimas internacionales- se encontraba generalmente en los circuitos locales y regionales, donde llegaban a forjarse en ocasiones las bases de grandes fortunas comerciales ${ }^{43}$. Y toda esta importancia del pequeño comercio fue así tanto en el ámbito urbano como, especialmente, en el rural. Al respecto, y aunque la investigación de los mercados rurales todavía parece incipiente en algunas zonas, los casos que ya se conocen (por ejemplo, en Cataluña, Valencia o Aragón) muestran la capacidad transformadora del comercio y el creciente nexo verificado entre el campesinado y las formas mercantiles, hasta el extremo de propiciar la aparición de auténticos campesinos-negociantes ${ }^{44}$. Pero también muestran la paulatina aparición de mercados de naturaleza diversa (de tierras, créditos, productos, rentas y trabajo), y el progresivo asentamiento de un entramado de villas que, con sus actividades diferenciadas, con los servicios ofrecidos a su área de influencia y con la centralización de operaciones económicas, des-

41. CAsado Alonso, H., «El comercio internacional castellano...», cit., pp. 651-652.

42. Sesma MuÑoz, J. A., «El comercio en la Edad Media...», cit., pp. 20-21, 27-28 y 36-37.

43. Hocquet, J.C., «Itinerarios comerciales», en Mediterraneum..., cit., p. 314; IguAL Luis, «Gran comerç i petit comerç...», cit.; Riera Melis, A., «El comerç català...», cit., p. 197; Diago Hernando, M., «El comercio en el interior de la península ibérica durante el reinado de Isabel la Católica», en «Isabel la Católica y su época»..., cit., pp. 789-806.

44. Sesma MuÑoz, J.Á., «Pequeñas ciudades y grandes villas en el ordenamiento del espacio aragonés», en «Les sociétés urbaines en France méridionale et en Péninsule Ibérique au Moyen Âge». Actes du Colloque de Pau, París, 1991, pp. 46-50. 
empeñaban la función de pequeñas ciudades de un microcosmos rural, al tiempo que eran puntos de enlace entre el campo y la verdadera ciudad-capital ${ }^{45}$.

Todas estas realidades, en buena lógica, dispersaron socialmente los efectos de un comercio que acabó por afectar a miles de familias. La definición de los protagonistas humanos del mercado puede reconstruirse explorando en profundidad su participación cotidiana en los tratos. No obstante, y particularmente para los mercaderes y hombres de negocios, esa reconstrucción también puede llevarse a cabo mediante la observación, por un lado, de la imagen que estos individuos tenían de sí mismos (como se lee en los famosos manuales de mercadería) y, por el otro, de la mirada sobre ellos de otros colectivos como los intelectuales cristianos. La combinación de estas distintas aproximaciones manifiesta una identidad social, ligada casi siempre a un determinado estilo de vida, en la que sobresalen muchas veces las confusiones de la caracterización documental y los contrastes entre la teoría y la práctica ${ }^{46}$.

Así, de entrada, una gran distancia material y cultural podía separar, por ejemplo, a un campesino que acudía más o menos esporádicamente al mercado de un agente extranjero que transitaba los caminos del naciente capitalismo. Como también podía ser muy evidente la divergencia de actividades y de técnicas entre un pequeño tendero y un gran mercader, o entre el gran mercader de una villa de tonalidad rural y el gran mercader de una metrópoli ${ }^{47}$. Sin embargo,

45. SAlRACH, J.M., «Sociedad rural y mercados en la Cataluña medieval», en Edad Media. Revista de Historia, 4 (2001), pp. 83-111; Guinot Rodríguez, E., «El mercado local en las pequeñas villas de la Corona de Aragón antes de la crisis bajo-medieval (siglos XI-XIV)», en Edad Media. Revista de Historia, 8 (2007), pp. 183-202. Como ejemplos concretos de mercados rurales en la Corona de Aragón, y sus enlaces a escala urbana, interesan análisis como los elaborados sobre el reino valenciano y, en particular, sobre Castellón, por Viciano, P., Senyors, pagesos i mercaders. El món rural valencià al segle xv, Catarroja-Barcelona, 2007, e Idem, Regir la cosa pública. Prohoms i poder local a la vila de Castelló (segles XIV-XV), Valencia, 2008, sobre todo pp. 197-224. A título comparativo véase, con carácter general, AsENJo GonzÁLEz, M., «El comercio...», cit., pp. 99-100, y PINTO, G., «I rapporti economici tra città e campagna», en GRECI et alii, Economie urbane..., cit., pp. 3-73. Y de modo más específico, Diago Hernando, M., «Comerciantes campesinos en la Castilla bajomedieval y moderna: La actividad mercantil de los yangüeses entre los siglos XIV y XVII», en Historia. Instituciones. Documentos, 32 (2005), pp. 115-144.

46. Navarro Espinach, G., «Los protagonistas del comercio: Oficios e identidades sociales en la España bajomedieval», en «El comercio en la Edad Media» ..., cit., pp. 147-187.

47. Un ejercicio comparativo entre grandes y pequeños operadores comerciales consta en IguAL LuIs, D., «De la tienda a la banca. Los agentes del comercio mediterráneo medieval», en Los vendedores y las civilizaciones, coord. por F. MASó FerRER, Barcelona, 2007, pp. 137-157. Aparte, buenos ejemplos de la actuación de pequeños y medianos negociantes urbanos en una ciudad como Barcelona figuran en Vela i Aulesa, C., L'obrador d'un apotecari medieval segons el llibre de comptes de Francesc ses Canes (Barcelona, 13781381), Barcelona, 2003, y en Idem, «Cobrar o no cobrar: la negociación en el comercio al por menor», en Negociar en la Edad Media / Négocier au Moyen Âge, ed. por Ma.T Ferrer Mallol et alii, Barcelona, 2005, pp. 553-570. Sobre la participación de sectores campesinos en el mercado, aparte de las citas de la nota 45, véase también Furió, A., «Las elites rurales en la Europa medieval y moderna. Una aproximación 
salvados estos extremos, y en un contexto donde el negocio se refería menos a las normas que a los valores y en el que la negociación comercial -indisociable del negocio- se fundaba sobre un juego complejo de dichos valores (de cambio, de precio y, en especial, de crédito ${ }^{48}$, la situación de muchos espacios euromediterráneos de la época se dibuja con contornos más imprecisos a la hora de llenar de contenido las diferentes profesiones que vertebraban el acto del intercambio. De ahí la ambigüedad que se ha llegado a apreciar, de nuevo en la Corona de Aragón, entre artesanos y tenderos, entre tenderos y mercaderes, o entre mercaderes y banqueros ${ }^{49}$. Sin duda, uno de los factores que influiría en este hecho es la promiscuidad que puede distinguirse por casi todos lados en la economía mercantil bajomedieval, en el sentido de que es problemático hallar en este ambiente personas especializadas en una única estrategia de negocios $\mathrm{y}$, a la inversa, sectores dominados por un único tipo de operadores ${ }^{50}$.

Incluso, entre los grupos internacionales que migraban siguiendo sus giros comerciales y financieros, la imprecisión y hasta la diversidad eran la norma. Como Giovanna Petti Balbi viene insistiendo para todo el Mediterráneo desde el siglo XIII, a partir del caso genovés, es innegable que muchos mercaderes foráneos constituyeron, en los lugares de asentamiento, comunidades o «naciones» homogeneizadas por rasgos culturales, lingüísticos e institucionales ${ }^{51}$. Por lo demás, la estructura de estas «naciones» se basaba en el parentesco, la confianza, el origen territorial, la identidad religiosa, la movilidad geográfica, y la eficacia de unas compañías de comercio que se presentaban como auténticas redes de empresa ${ }^{52}$. De hecho, no faltan los autores que, en relación con

de conjunto», en El lugar del campesino. En torno a la obra de Reyna Pastor, ed. por A. RodRíGUEz, Valencia, 2007, pp. 391-421.

48. Genet, J.-Ph., «Négocier: vers la constitution de normes», en Negociar en la Edad Media..., cit., pp. 583584.

49. Igual Luis, D., «De la tienda a la banca...», cit., pp. 141-144 y 155-157; Idem, «Los agentes de la banca internacional: cambistas y mercaderes en Valencia», Revista d'Història Medieval, 11 (2000), pp. 105-138; NAVARro Espinach, G., «La cultura material de los artesanos castellonenses en el siglo XV», en Boletín de la Sociedad Castellonense de Cultura, 81 (2005), pp. 406-408.

50. CASSANDro, M., «Caratteri dell'attività bancaria fiorentina nei secoli XV e XVI», en Banchi pubblici, banchi privati e monti di pietà nell'Europa preindustriale. Amministrazione, tecniche operative e ruoli economici. Atti del Convegno, Génova, 1991, vol. I, pp. 341-366, sobre todo pp. 343-345.

51. Рetti Balbi, G., Negoziare fuori patria..., cit., p. 4 y pássim; «Un sistema di negoziazioni politico-commerciali: I consolati genovesi nel Basso Medioevo», en Negociar en la Edad Media..., cit., pp. 475-487.

52. Iradiel Murugarren, P., «El siglo de oro del comercio valenciano», en El comercio y el Mediterráneo. Valencia y la cultura del mar, coord. por I. AguILAR CivERA, Valencia, 2006, pp. 124-125; Comunità forestiere e «nationes» nell'Europa dei secoli XIII-XVI, a cura di G. Petti Balbi, Nápoles, 2001; Molho A., Ramada Curto, D., «Les réseaux marchands à l'époque moderne», en Annales. Histoire, Sciences Sociales, $58^{\mathrm{e}}$ année, $n^{\circ} 3$ (2003), pp. 569-579. Por su interés respecto a los mecanimos, territoriales e institucionales, que articulaban en el Mediterráneo la circulación y el asentamiento de operadores extranjeros en las realidades 
estas redes, dividen los network makers (es decir, los artífices de las mismas, entre quienes sobresalen los mercaderes italianos) de los network takers (otros grupos también expandidos internacionalmente, pero que tomaban o utilizaban redes ajenas). O que llegan a fundamentar los elementos de colaboración o de concurrencia que podían darse no sólo entre redes «nacionales» distintas, sino incluso dentro de una red de agentes del mismo origen ${ }^{53}$. Siendo cierto todo esto, no es menos verdad que, en las migraciones mercantiles, al menos por lo demostrado en las colonias extranjeras del Mediterráneo ibérico, ni la totalidad de sus miembros eran élites, ni desarrollaban los mismos comportamientos sociales y estrategias económicas, ni se ocupaban sólo de las grandes transacciones exteriores ${ }^{54}$.

Angela Orlandi, refiriéndose a la sede de la empresa toscana de Francesco Datini en Valencia entre 1395-1398, ha recalcado que la separación entre comercio minorista y comercio mayorista únicamente era perceptible entonces entre los operadores más pequeños. Para los actores medianos y mayores del mercado, lo habitual era que ambos tipos de intercambio fueran desarrollados por la misma compañía, lo que significa que sus empleados -en persona o a través de intermediarios - intervenían donde podían y por cualquier cantidad de producto. $Y$ tal variedad de intereses obligaba a empresas como la de Datini, que -como es sabido-participaba en las exportaciones e importaciones marítimas valencianas,

locales, conviene no perder de vista el libro Constable, O.R., Housing the Stranger in the Mediterranean World. Lodging, Trade, and Travel in Late Antiquity and the Middle Ages, Cambridge, 2003, y el artículo Calabi, D. Keene, D., «Merchants' lodgings and cultural exchange», en Cities and Cultural Exchange in Europe..., cit., pp. 315-348.

53. Stabel, P., «Italian Merchants in 15th-Century Bruges and 16th-Century Antwerp: Trade and Social Integration» (sobre la división network makers / network takers), y Guidi-Bruscoli, F., «The Network of Florentine Merchant-Banking Companies in the North of Europe: Collaboration vs Competition» (sobre los factores de colaboración y concurrencia entre redes), comunicaciones 1121-b y 1121-c presentadas a la sesión 1121 (Cities in Medieval Italy and Italians in Medieval Cities. V: Across the Great Divide - Merchants and Cities in Trans-alpine Trade), del International Medieval Congress, Leeds, julio de 2007.

54. IGuAl Luis, D., «La emigración genovesa hacia el Mediterráneo bajomedieval...», cit., pp. 295-328; ID., «Banqueros y comerciantes italianos en España...», cit., pp. 157-161. Sobre la diversidad de comportamientos sociales entre los mercaderes extranjeros de la Península Ibérica, interesan los trabajos recientes de M.E Soldani sobre los toscanos de Barcelona, como «Alleanze matrimoniali e strategie patrimoniali nella Barcellona del XV secolo: I mercanti toscani fra integrazione e consolidamento della ricchezza», en Archivio Storico Italiano, CLXII, no 602/IV (2004), pp. 667-696, o «Da Accettanti a Setantí: Il processo di integrazione di una famiglia lucchese nella società barcellonese del Quattrocento», en Per Marco Tangheroni. Studi su Pisa e sul Mediterraneo medievale offerti dai suoi ultimi allievi, a cura di C. IANNELLA, Pisa, 2006, pp. 209-233. Esta autora ha justificado la imposibilidad de delinear una estrategia social unívoca, de grupo o comunidad, entre los toscanos asentados en la capital catalana, a causa de las diferencias personales que nacían del origen y la especialización profesional, del peso económico y político de cada sujeto en la ciudad de instalación, y de la calidad de los vínculos conservados con la madre patria. 
a poseer también tiendas urbanas de venta al detalle, fuera cual fuera el porcentaje de inversión que dedicaran a esta actividad ${ }^{55}$.

Pienso que esto último (lo del porcentaje que una empresa podía reservar a la distribución al por menor) nos sitúa en una línea de problemas e interrogantes bastante significativos. Para muchos de los componentes sociales del mercado bajomedieval, sobre todo los de escala inferior, ¿cuál era el relieve auténtico de sus gestiones comerciales? Para mercaderes, agentes y empresas como la que he citado de Datini, ¿qué repercusión tenía en sus balances económicos la relación entre pequeño comercio y gran comercio? En general, y desde la perspectiva de la realidad económica global, ¿cómo se articulaba la jerarquía entre estos dos comercios (el pequeño y el grande)? O dicho de otra manera: ¿qué pesaba más en las sociedades bajomedievales mediterráneas: el tráfico local y regional o el tráfico internacional?

No entraré a fondo en las polémicas que plantean estas preguntas, en particular la última de ellas. Las discusiones al respecto tienen ya un largo recorrido y los argumentos que se podrían emplear son tantos que, simplemente, me faltaría tiempo para exponerlos todos ${ }^{56}$. Pese a esto, sí quisiera decir que creo que un punto clave del debate (y de la respuesta a las cuestiones anotadas) radica en la consideración del tema en términos cuantitativos o cualitativos, ya sea buscando cifras concluyentes sobre la suma de recursos y actividades empleados en los diferentes ámbitos comerciales, o ya sea, en paralelo, investigando casi mejor las condiciones de estímulo, incidencia y arrastre de cada sector sobre el conjunto del sistema económico ${ }^{57}$.

Por descontado, para examinar la economía medieval, es básico atender a la cuantificación numérica del movimiento comercial $^{58}$. Pero los cálculos oportunos o no abundan (muchas veces por carencia de fuentes adecuadas) o, cuando existen, cabe plantear sobre ellos dudas de valoración y hasta de fundamentación heurística. ¿Por qué? Dos estudiosos británicos (Christopher Dyer y Richard

55. ORLANDI, A., «Estudi introductori», cit., pp. 42-43.

56. Dichas discusiones continúan abiertas, y probablemente lo seguirán estando durante mucho tiempo. Así se pudo comprobar en la mesa redonda Pratiques de gestion des acteurs économiques: de l'entreprise au territoire (XIV $V^{e} X V I I^{e}$ siècle), celebrada en París el 23 y 24 de noviembre de 2007, bajo la organización del Institut d'Histoire Moderne et Contemporaine (CNRS-ENS) y de la Université Paris 7 - Denis Diderot. Sobre la cuestión, particularmente fructíferas fueron las comunicaciones de CH. DyeR ( «John Heritage and his country: connecting a region with the international market») y M. STEINBRINK («Layers of trade and credit. Ulrich Meltinger's account book as basis for an analysis of Late Medieval credit relationships»).

57. Tangheroni, M., Commercio e navigazione ..., cit., p. 255; Tognetti, S., «Uno scambio diseguale. Aspetti dei rapporti commerciali tra Firenze e Napoli nella seconda metà del Quattrocento», en Archivio Storico Italiano, CLVIII, no 585/III (2000), pp. 461-464.

58. Abulafia, D., «Mercati e mercanti nella Corona d'Aragona ...», cit., p. 803. 
Britnell) han subrayado en publicaciones recientes algunas obviedades, pero que me da la impresión que los historiadores del comercio olvidamos con demasiada frecuencia. En la visión de la Edad Media que hoy tenemos hay un índice probablemente alto de comercio oculto, bien porque no comparece por lo que sea en la documentación conservada, bien porque era un comercio no institucionalizado y que huía de la concreción en mercados formales y controlados ${ }^{59}$. Éste sería el llamado «comercio informal» (itinerante, entre vecinos, en tabernas o en posadas), que creció y se mantuvo en Europa desde el siglo XI como medio de cerrar innumerables pequeñas transacciones a las que no compensaba el esfuerzo y el gasto de ser realizadas en un mercado o una feria. De hecho, a partir de la situación inglesa se ha llegado a pensar que, juntando campo y ciudad, la proporción del comercio que pasaba por mercados formalizados debió ser bastante menos de la mitad de todos los tratos mercantiles necesarios para sostener la economía medieval en cualquier etapa de su desarrollo. Sea como fuere, dicho intercambio informal venía favorecido por fuertes relaciones sociales y por vínculos de reciprocidad e interdependencia, e incluso se apoyaba en el propio mercado formal, ya que éste le suministraba información regular sobre precios, por ejemplo ${ }^{60}$.

Ante circunstancias como las que acabo de señalar, me parece normal que la controversia sobre la jerarquía entre el pequeño y el gran comercio, entre lo local y lo internacional, se haya centrado en datos cuantitativos indirectos o parciales $\mathrm{o}$, sin más, en datos cualitativos. Y entre esos datos cualitativos, aparte de las citadas condiciones de estímulo o incidencia sobre el sistema económico, habría que insistir una vez más en las interacciones establecidas de manera creciente durante la Baja Edad Media entre ambos niveles del mercado. Esto rebaja la lógica de confrontación con que se ha acostumbrado a leer la realidad de los dos sectores y, de paso, convierte en ficticia hasta cierto punto la dicotomía entre ellos, en beneficio de una interpretación integrada y reticular de los espacios mercantiles en la que también tendría cabida la emergencia de redes intermedias de mercado, muy consistentes a escala regional, como las verificadas en áreas que concentraban la producción de alimentos o de materias primas exportables ${ }^{61}$.

59. Dyer, CH. «The Consumer and the Market...», cit., pp. 278-279; Idem, «The Hidden Trade of the Middle Ages: Evidence from the West Midlands», en Idem, Everyday Life..., cit., pp. 301-303.

60. BritnelL, R., «Uses of money in medieval Britain», en Medieval Money Matters, ed. by D. Wood, Oxford, 2004, p. 17; Idem, «Markets, shops, inns, taverns and private houses in medieval English trade», en Buyers and Sellers..., cit., pp. 109-121. Sobre el tema del comercio informal, véase también STABEL, P., «From the market to the shop...», cit., pp. 101-103.

61. Lo afirmado en los últimos párrafos, sobre las relaciones y jerarquías entre el pequeño y el gran comercio medievales, puede complementarse con lo que ya he señalado, en el mismo sentido y de modo más amplio, en IGual LuIs, D., «¿Crisis? ¿Qué crisis?...», cit., pp. 221-223, y en Idem, «Gran comerç i petit comerç...», cit. 


\section{UNA APROXIMACIÓN A LOS ESPACIOS Y LOS PROTAGONISTAS DEL MERCADO LOCAL}

Paso a la tercera parte del texto, dedicada a observar el comercio local y sus posibles lazos con otras categorías de intercambio. Que se hable de los vínculos entre esas diversas categorías no significa, ni mucho menos, que todas exhibieran las mismas características. Además de diferencias evidentes de magnitud, entre el pequeño y el gran comercio solía haber una distinción de escenarios y hasta de operadores, no tanto de productos circulantes ${ }^{62}$.

Quizá, si tuviéramos que ofrecer un retrato inicial del ámbito local del mercado, éste comenzaría por reconocer la cotidianidad de su desarrollo, la inmediatez del tráfico efectuado en él, y la proximidad de espacios y protagonistas. Tales rasgos pueden apreciarse en la actividad de pequeños puertos costeros que, de forma modesta y a través del cabotaje, negociaban con sus vecinos el transporte de mercancías de uso habitual ${ }^{63}$. Pero dichos elementos también son visibles en tres de los instrumentos básicos del comercio bajomedieval en el Mediterráneo cristiano, que ya he citado varias veces hasta aquí: la tienda diaria (que era, en ocasiones, tiendataller), el mercado (de celebración semanal) y la feria (de celebración anual).

En las ciudades y otros núcleos semiurbanos, el emplazamiento físico de estos instrumentos condujo a una verdadera «topografía del intercambio». Ésta era producto $-\mathrm{y}$ productora a su vez- de significados sociales, y expresaba relaciones poco visibles que no suelen comparecer en las fuentes escritas que han llegado hasta nosotros ${ }^{64}$. En esa topografía, al menos para el caso italiano, se ha distinguido una progresiva diferenciación formal y funcional. Hasta el siglo XV, las tareas económicas, los eventos culturales y religiosos y las ceremonias políticas y jurídicas se mezclaban materialmente en los mismos espacios ciudadanos, en las mismas calles y en las mismas plazas. Sin embargo, ya desde finales del Cuatrocientos, tanto en los grandes centros comerciales de la Italia septentrional como en los focos medianos, se fue concretando una separación que segregó los lugares del mercado de los de la acción política, por ejemplo ${ }^{65}$.

62. Ait, I., Il commercio..., cit., pp. 25-26; Balard, «Comercio local...», cit., p. 269; Tangheroni, M., Commercio e navigazione..., cit., p. 394.

63. HocQuet, J.C., «Itinerarios comerciales», cit., pp. 314-315; Alemany, J., «Puertos y ciudades portuarias mediterráneas en la Baja Edad Media», en Mediterraneum ..., cit., pp. 425-449; «Ports maritimes et ports fluviaux au Moyen Âge». XXXVE Congrès de la Société des historiens médiévistes de l'Enseignement supérieur public, París, 2005.

64. Calabi, D. Turk Christensen, S., «Volume editors' preface», en Cities and Cultural Exchange in Europe..., cit., p. XXVI; Boone, M. Porfyriou, H., «Markets, squares, streets: urban space, a tool for cultural exchange», en Ibidem, p. 227.

65. CAlaBI, D., «Renewal of the shop system: Italy in the early modern period», en Buyers and Sellers..., cit., pp. 51-55. 
Es muy probable que procesos similares se dieran en otras partes de Europa occidental, aunque fuera con cronologías divergentes. Así lo ha apuntado Miguel Ángel Ladero para las ciudades de la Corona de Castilla entre los siglos xII y $\mathrm{XV}^{66}$. Y así parecen indicarlo también algunos datos que se conocen para el mismo Bajo Medievo en un territorio como el valenciano.

En Valencia capital, y dejando de lado el asentamiento litoral del grao (con su correspondiente cargadero de mercancías), las bases de la actividad mercantil se situaban entonces en las calles que reunían los obradores y las tiendas de determinados oficios, como la draperia, la corretgeria, la argenteria, la fusteria o la tapineria. Pero también se situaban en el almudín para el depósito y el reparto de cereal, las panaderías, las carnicerías, las pescaderías y las tabernas urbanas; en las plazas que concentraban las ventas de distintos productos agrícolas, como frutas, hierbas, ajos o cebollas; en la propia ubicación del mercado semanal, fijada por Jaime I entre la muralla y el denominado arrabal de la Boatella; en algunas alhóndigas, que podían desempeñar misiones de hospedaje de comerciantes y hasta de almacenaje y venta de mercancías; y en la lonja, cómo no, tanto la vieja lonja de mercaderes o del aceite (que dataría de las primeras décadas del XIV) como la nueva lonja de la seda (completada en 1498) ${ }^{67}$.

Siguiendo en área valenciana, en una villa como Castellón (que contó a inicios del siglo XV con alrededor de un millar de fuegos), también las calles y plazas experimentaron la dinámica comercial, sobre todo cuando se celebraban el mercado y la feria. En el Trescientos está demostrado que, en tal feria, se congregaban bruneters (vendedores de brunetes, telas teñidas en tonos muy oscuros), merceros, cerrajeros, peleteros, asters (vendedores de astes o lanzas), candeleros, negociadores de paños y pieles, y tenderos sin más ${ }^{68}$. Y a los puestos montados por estos oficios, las regulaciones municipales añaden los que podían instalar en Castellón los dueños de animales, las panaderas, los vendedores de hierba y hortalizas, los hortelanos que traían cebollas o los vendedores de paños de lana. Seguramente, muchos de estos puntos de distribución eran simples tenderetes al aire libre. Junto a ellos también existían las tiendas permanentes, vinculadas a las casas de los tenderos o a los talleres de los artesanos. En este segundo caso, la especialización del trabajador revelaba los productos que la tienda

66. Ladero Quesada, M.Á., «Economía mercantil y espacio urbano: ciudades de la Corona de Castilla en los siglos XII a XV», en Boletín de la Real Academia de la Historia, CXCI, cuaderno II (1994), pp. 288-289.

67. Cruselles Gómez, E., Los mercaderes de Valencia en la edad media (1380-1450), Lérida, 2001, pp. 254256 y 262-263; García Marsilla, J.V., La jerarquía de la mesa. Los sistemas alimentarios en la Valencia bajomedieval, Valencia, 1993, pp. 104-121; Historia de Valencia, dir. por A. Furió, Valencia, 1999, pp. 95-99, 110-113 y 163-164.

68. SÁnchez Adell, J., Castellón de la Plana en la Baja Edad Media, Castellón, 1982, pp. 125-128. 
ofrecía, aunque la documentación castellonense declara a veces explícitamente los objetos de venta de estos lugares: paños, tintes, paja, algarrobas o cebada. De modo semejante, las mismas fuentes denotan el interés de las autoridades locales por garantizar el suministro de trigo, sal, carne o pescado. Y tal propósito explica la preocupación del municipio por estimular en Castellón, como mínimo desde fines del XIV, la presencia de carniceros en las carnicerías y de pescadores, mercaderes y revendedores que trajeran pescado a la población. Pero también justifica la creación oficial de un almudín y, desde inicios del Cuatrocientos, de dos tiendas: una del trigo y otra de la $\mathrm{sal}^{69}$.

Sin duda, con todas estas realidades, ciudades y villas como las que he mencionado aseguraban la constancia del movimiento mercantil y la confluencia en su seno de muchos y variados agentes: desde productores artesanales y campesinos hasta mercaderes, pasando -como en Valencia o Castellón de nuevo-por tenderos, hostaleros, revendedores, o corredores que terciaban entre las partes contratantes de una compraventa. Una confluencia (de esa multitud y variedad de operadores) que se hace patente en cualquier testimonio del desarrollo concreto de la vida comercial. Si queremos más ejemplos, y por seguir en la Corona de Aragón, en la feria y el mercado medievales de Vic los puestos de distribución se agrupaban por especialidades: zapateros, fabricantes de corazas, merceros, cuchilleros, vendedores de lino y paños, carniceros, vendedores de aceite, distribuidores de objetos de carretería, y tratantes de innumerables cosechas agrícolas ${ }^{70}$. Mientras, en la Tarragona de 1348, la ordenación de la feria comenzaba con el compromiso de los corredores de cumplir bien con su oficio. Una vez inaugurado el encuentro, en él se llevaban a cabo las transacciones relacionadas sucesivamente con el textil, con el cuero, con los productos alimenticios y con el ganado y otros bienes. La feria se cerraba con el ajuste financiero de los pagos y contratos que se hubieran generado ${ }^{71}$.

Como he comentado en un momento anterior, las ferias (y casi lo mismo podría alegarse para las tiendas y los mercados) animaban el ambiente local y, a veces, conectaban también ese ambiente con los sectores del tráfico regional e internacional, incluso aunque fuera con matices. Según el profesor Sesma, en las tierras turolenses, donde los efectos del comercio exterior desde 1250 fueron muy significativos para la población rural y semiurbana, el papel de las ferias en rela-

69. Iradiel Murugarren, P. et alii, Oficios artesanales y comercio en Castelló de la Plana (1371-1527), Castellón, 1995, pássim, pero sobre todo pp. 113-136.

70. Ollich, I., Camp i ciutat a la Catalunya del segle XIII. L'evolució de la Plana de Vic, Vic, 1988, p. 43; Batlle i Gallart, C., Fires i mercats, factors de dinamisme econòmic i centres de sociabilitat (segles XI a XV), Barcelona, 2004, pp. 127-128.

71. Serrano Coll, M., Lozano López, E., «El mercader y su entorno en la Corona de Aragón», en Los vendedores y las civilizaciones, cit., pp. 118-120. 
ción justamente con ese comercio exterior era canalizar las importaciones, porque la exportación de lana y otros artículos - que era esencial para la zona- no se desplegó completamente dentro de dichas ferias. En realidad, desde fechas tempranas (en torno a 1330), el circuito lanero se organizó a través de acuerdos directos entre ganaderos y mercaderes aragoneses, quienes empleaban el mecanismo de las compras anticipadas. A esta estructura se incorporaron con intensidad desde 1370 negociadores foráneos como los italianos, que o contactaban también directamente con los ganaderos, o se veían obligados a recurrir a la intermediación de unos agentes autóctonos que intentaban controlar la producción interna ${ }^{72}$.

Siempre según José Ángel Sesma, el trato de la lana -por lo que tenía de abastecimiento de industrias peninsulares y europeas- demuestra como pocos hasta qué punto las condiciones de desarrollo de una economía local podían relacionarse con las fluctuaciones de mercados cada vez más alejados ${ }^{73}$. Además, en esa línea, la capacidad de penetración en un espacio dado de comerciantes extranjeros, y la ramificación social y territorial de sus intereses, serían pruebas asimismo de las interferencias verificadas entre distintos niveles del mercado. Si continuamos con el ejemplo de los operadores italianos, su actuación en la Valencia del siglo XV alrededor de productos como la lana, el pastel o los tejidos indica una presencia no limitada a la exportación o la importación marítimas, sino también muy activa en los negocios al por menor y en las corrientes de circulación internas a la capital y al reino, como ya sabemos que hacía la empresa Datini a fines del $\mathrm{XIV}^{74}$. Aparte, para otro caso mediterráneo como el de la ciudad de Nápoles durante la Baja Edad Media, Amedeo Feniello ha revelado que los mercaderes extranjeros, del resto de Italia o de la Corona de Aragón, construyeron por sí mismos un doble sistema de aprovisionamiento: el ligado a grandes intercambios regionales y a amplias redes distribuidoras, pero también el vinculado a una escala local que, mediante la unión con los propietarios agrícolas napolitanos, permitía el suministro directo, seguro y constante de la urbe ${ }^{75}$.

Todas estas imágenes, y otras que se podrían añadir, insisten en algo que viene diciendo David Abulafia desde hace tiempo. En las economías mediterráneas,

72. Sesma MuÑoz, J.Á., «Producción para el mercado, comercio y desarrollo mercantil en espacios interiores (1250-1350): el modelo del sur de Aragón», en «Europa en los umbrales de la crisis (1250-1350)». XXI Semana de Estudios Medievales de Estella, Pamplona, 1995, pp. 226-227 y 242-243; Idem, «Centros de producción y redes de distribución en los espacios interiores de la Corona de Aragón: materias primas y productos básicos», en XVIII Congrés Internacional d'Història de la Corona d'Aragó ..., cit., pp. 916-918.

73. Sesma Muñoz, J. Á., «Producción para el mercado ...», cit., pp. 242-243.

74. IGuAL LuIs, D., Valencia e Italia en el siglo XV. Rutas, mercados y hombres de negocios en el espacio económico del Mediterráneo occidental, Castellón, 1998, pp. 303-418; Idem, «La difusión de productos ...», cit., pp. 477-489.

75. Feniello, A., Les campagnes napolitaines à la fin du Moyen Âge. Mutations d'un paysage rural, Roma, 2005 , p. 218. 
los mercaderes extranjeros no rehusaban insertarse en tráficos secundarios, incluso en ocasiones desgajados total o parcialmente de los tráficos mayores. A la vez, la demanda internacional que estos mercaderes representaban podía ayudar a la configuración de las economías locales ${ }^{76}$, si bien aquí habría que diferenciar las situaciones en que dicha configuración se resolvía en cooperación con los grupos mercantiles autóctonos, o implicaba una colisión con los intereses y las expectativas de crecimiento de tales grupos. Aunque con las lógicas oscilaciones coyunturales, si la Valencia del Cuatrocientos respondería a un modelo de comportamiento del primer tipo (el de la cooperación) ${ }^{77}$, lo que ocurre en Barcelona (entre los siglos XIII y XV) ${ }^{78}$ y en la Nápoles retratada por el mencionado Amedeo Feniello (durante el Xv) ${ }^{79}$ parece estar más en la línea del choque entre foráneos y autóctonos. Todo esto puede confirmarse en el terreno institucional y de la política económica, con la adopción según los casos -y las instancias de poder- de normas proteccionistas y mercantilistas o, por el contrario, de medidas de concesión de exenciones, de facilidades de tránsito, de apertura de espacios y de recorte de gastos con el fin de colocar en el mercado excedentes comercializables ${ }^{80}$. Pero también tendría otras derivaciones, como las comprobadas a través de algunas técnicas de los negocios. Así, por ejemplo, entre los mercaderes italianos presentes en varias partes del Mediterráneo, se difundió la práctica del trueque o baratto como medio de favorecer el trato comercial, de imponer la circulación de los propios productos italianos y, a veces, de someter a los agentes locales a una relación de dependencia ante su escasa capacidad financiera y de conocimiento de los mercados ${ }^{81}$.

76. AbulafiA, D., «Mercati e mercanti nella Corona d'Aragona ...», cit., pp. 810 y 814-816; Idem, «Gli italiani fuori d'Italia», en Gli orizzonti aperti. Profili del mercante medievale, a cura di G. AIRALDI, Turín, 1997 , pp. 197-198.

77. Igual Luis, D., Valencia e Italia ..., cit., pp. 55-76; Idem, «Política y economía durante la Baja Edad Media. El papel de la monarquía en el comercio exterior valenciano», en Los cimientos del Estado en la Edad Media. Cancillerías, notariado y privilegios reales en la construcción del Estado en la Edad Media, ed. por J.A. Barrio Barrio, Alcoy, 2004, pp. 264-267.

78. Ferrer i Mallol, $M^{\mathrm{a}}$.T., «Els italians a terres catalanes (segles XII-XV)», en Anuario de Estudios Medievales, 10 (1980), pp. 428-453; Del Treppo, M., Els mercaders catalans ..., cit., pp. 255-277.

79. Feniello, A., Les campagnes napolitaines..., cit., pp. 12 y 215-217; Idem, «Entre marché international et marginalisation: le réseau commercial napolitain dans la seconde moitié du XVe siècle», comunicación presentada a la mesa redonda Pratiques de gestion des acteurs économiques: de l'entreprise au territoire..., cit.

80. Iradiel Murugarren, P., «El siglo de oro...», cit., p. 124. A escala europea, la distinta actitud de las sociedades locales ante el movimiento de agentes económicos extranjeros se comprueba bien en el volumen Cities and cultural exchange in Europe ..., cit., especialmente con el artículo de AmELANG, J.S., «Cities and foreigners», pp. 42-55, y con los estudios incluidos en la segunda parte del libro («Presence and reception of foreigners», pp. 57-193).

81. Tognetti, S., «Uno scambio diseguale ...», cit., pp. 464-465; Dini, B., Una pratica di mercatura in formazione (1394-1395), Florencia, 1980, pp. 19-20 y 37. El recurso que menciono al trueque demuestra, de 
En cualquier caso, frente a las informaciones que vengo resumiendo sobre los enlaces entre macrocircuitos y microcircuitos del comercio, en otras oportunidades se hace más complicado documentar (o entender) en qué medida, para qué mercancías y en qué áreas esos nexos se producían o, por el contrario, cada sector estaba al servicio de intercambios cerrados sustancialmente sobre sí mismos. Y este interrogante puede plantearse, muy en especial, para los mecanismos con los que se construían las vías marítimas del transporte.

Al respecto de esto último, el espacio valenciano vuelve a brindar imágenes relevantes, a través de la observación no tanto del puerto de la capital como de los embarcaderos del norte (Castellón) y del sur (Alicante) del territorio. En el siglo XV, estos embarcaderos aparecían más o menos integrados en rutas comerciales de radio medio o largo, exteriores al reino. La organización de estas rutas, sobre todo en los puertos alicantinos, dependía en ocasiones de negocios dirigidos desde la ciudad de Valencia, o de la combinación entre esas mismas rutas largas y otros trayectos menores engarzados con la propia Valencia, trayectos que vertebraban la proyección de exportaciones o la distribución de importaciones. Frente a estos itinerarios, los cargaderos regnícolas también fueron a fines de la Edad Media el centro de circulaciones cortas, que llegaban desde las comarcas septentrionales y meridionales sólo a la capital, y que se consagraban al abastecimiento de los grupos urbanos. Desde Alicante, en estas circulaciones aún es posible notar cierto eco del comercio internacional, gracias a la presencia esporádica en los cargamentos de partidas italianas o flamencas. Pero, desde Castellón, los transportes interiores reflejarían una lógica bilateral casi en exclusiva con Valencia, ya que se destinaban únicamente a sacar excedentes rurales y a satisfacer las necesidades alimentarias de la metrópoli ${ }^{82}$.

Además, precisamente, el estudio detallado del circuito marítimo que unía los puertos castellonenses con Valencia durante la segunda mitad del siglo XV demuestra otras cuestiones de interés sobre la articulación en la época del pequeño comercio mediterráneo ${ }^{83}$. Primera cuestión, la alta densidad que manifesta-

paso, que éste, por muy ineficiente que pueda juzgarse, no sólo no había desaparecido del comercio de finales de la Edad Media, sino que formaba parte habitual de su funcionamiento y a él acudían incluso las élites mercantiles europeas. Sobre este tema, véase con más detalle ABULAFIA, D., «L'economia italiana ...», cit., p. 370; Bolton, J., «What is money? What is a money economy? When did a money economy emerge in medieval England?», en Medieval Money Matters, cit., pp. 6-7; y D. IGUAL LuIs, «Los medios de pago en el comercio hispánico (siglos XIV y Xv)», en «El comercio en la Edad Media» ..., cit., pp. 262-267.

82. IguAl Luis, D., «Gran comerç i petit comerç ...», cit. En relación con los puertos alicantinos, compruébese el efecto del comercio flamenco también en Hinojosa Montalvo, J., De Valencia a Flandes. La nave della frutta, Valencia, 2007, especialmente pp. 116-169.

83. Véase dicho estudio en Igual Luis, D., Soler Milla, J.L., «Una aproximació al comerç marítim de les comarques castellonenques (segles XIII-Xv)», Millars. Espai i Història, 29 (2006), pp. 104-132. 
ban las rutas navales en las cercanías del litoral: sólo en tres años, discontinuos pero próximos entre sí (1488, 1491 y 1494), las fuentes fiscales han permitido sumar alrededor de trescientos desplazamientos de embarcaciones de Castellón a Valencia. Aunque es cierto que la abundancia de una corriente de intercambio no siempre guarda relación directa con su peso económico, creo que estos números (trescientos viajes en tres años) no son desdeñables. Segunda cuestión, el transporte básico que estos desplazamientos hacían de mercancías humildes: en 1488 , los seis productos que más abundaron en los envíos castellonenses fueron cebada, habas, miel, aceite, hordio y trigo. Tales mercancías se contrataban con notable frecuencia y en forma de partidas modestas que, dado su volumen y valor reducidos, se justificaban por la mera transferencia comercial entre un exportador y un importador, alejándose así de potenciales redistribuciones posteriores. Tercera y última cuestión, la gran variedad de actores que protagonizaban este circuito, la mayoría de origen castellonense o valenciano y muchos de ellos no especializados en el mercado. De hecho, entre quienes intervinieron en los negocios marítimos entre Castellón y Valencia encontramos mercaderes de niveles económicos bastante diversos, pero también marinos y patrones, artesanos, labradores enriquecidos, y miembros privilegiados o de élite de las comunidades (nobles, eclesiásticos y autoridades locales).

Desde luego, lo que acontecía en los puertos castellonenses no era nada extraordinario. El conocimiento que se tiene del funcionamiento comercial de otros cargaderos, pequeños o medianos, a lo largo del Occidente mediterráneo va en una línea muy similar a la que acabo de exponer. Pienso, por ejemplo, en algunos trabajos recientes que se han efectuado sobre puertos de la costa catalana entre los siglos XIV y $\mathrm{XV}^{84}$. Todo ello era el resultado de las extensas tramas comunicativas y de transporte existentes en el mar interior, aunque también era la consecuencia de las especializaciones productivas locales y del aumento de la capacidad de consumo que experimentaron las poblaciones europeas de finales de la Edad Media. Como espero que se haya comprobado en mi texto, tal situación incrementó la magnitud de la pequeña circulación económica. Y esta circulación, con independencia de la vinculación más o menos clara que estableciera con el gran comercio, pasó a ser ya un engranaje básico en el comercio de la época y que, junto al tráfico internacional, no debe ser olvidado en ningún caso.

84. Me refiero a sendas comunicaciones incluidas en XVIII Congrés Internacional d'Història de la Corona d'Aragó ..., cit., vol. II: las de Guillère, Ch., Pinto, A., «Le port de Sant Feliu de Guíxols et l'expansion catalane (1340-fin du XVe siècle)» (pp. 1233-1248), y Soldevila i Temporal, X., «Des de Gènova fins a València: el cabotatge empordanès i selvatà als segles XIII i XIV» (pp. 1291-1306). Pero, siempre en relación con la costa catalana, no se olviden las obras de Zucchitello, M., El comerç marítim de Tossa a través del port barceloní (1357-1553), Tossa, 1982, e Idem, Homes, vaixells i mercaderies de Tossa al Grau de València (1459-1703), Tossa, 1991. 